\title{
Teacher attitudes in the design of learning activities through technology
}

\author{
R. Martinez-Lopez ${ }^{1,2}$, C. Yot $^{2}$, M. Sacchini ${ }^{1}$ \\ ${ }^{1}$ Samara National Research University, 34 Moskovskoe Shosse, 443086, Samara, Russia \\ ${ }^{2}$ Universidad de Sevilla, C/Pirotecnia s/n, Sevilla 41013, Spain
}

\begin{abstract}
This study explores the use of technology in the design of learning activities by Russian teachers and their relationship with the technology self-efficacy in higher education. The Inventory of Learning Activities with Technologies in the University was translated and adapted to Russian context and validated by retest method. Answers were classified through content analysis. Findings suggest that access to technology, on-line courses, and data elaboration software among teachers should be enhanced. Teachers' self-confidence and use of technologies are related: one increases the level of another and vice-versa.
\end{abstract}

Keywords: learning activity; teacher, attitude; self confidence; technology use; supercomputing education; high performance computing; open question; Russian university

\section{Introduction}

Since supercomputing is considered a strategic area [1], the relevance of supercomputing education is increasing [2, 3]. The effort taken by Russia is justified [4, 5]. Nevertheless, despite its success, it is considered that improvement could be developed [6]. An analysis of the state of things of 2010 [4], showed that supercomputing education is narrowed to studying only several simple technological subjects at the University. Due to that, an appropriate education of users in supercomputer centers is critically low [3]. A recent analysis of the current state of the High Performance Computing (HPC) and Computational Science research [7], briefly highlighted the necessary scalability at all levels and highly trained computational scientists with the ability and skills to approach complex scientific problems.

The skills necessity claim of specialists in supercomputing [7], are not new. The workforce and the technology disparity has been researched for a long time [9]. Proposals to bridge the skills gap have covered, for example, the HPC competency as a requirement in the research and engineering curricula [1]. Following this approximation, the unification of skills at the university level and advanced research methodology has been proposed [10,7], curriculum contents and knowledge assessment integration [11]. Other studies have been focused on the diffusion of supercomputing education to improve the use of supercomputer systems and the change of the higher educational system [3]. Proposals and research have tended to focus on the skills and knowledge required in a wide range of computer science issues of a specialist nature in the area of supercomputing technologies [7], rather than attitudes. For example, the recent analyses about training students in clusters competition in Thailandia, found that attitude is one of the missing elements [8], due to the Thai personality characteristics, only interested students counted.

Studies on the learners and the teachers could help to determine if they are ready for a new technology [12]. Student-centered approaches to learning have encouraged teachers to integrate technologies into their teaching. Empirical research reported that teacher attitudes and personal use of technology, accounted for 55\% of the variance [13]. Considering teachers as facilitators, the incorporation of technology into their teaching is critical [14]. In fact, it is necessary to understand how the implementation of a technology could improve the perceived competence and use of teachers in their teaching [15]. Recent research to determine the possibilities of using technology in high education highlighted the increase of favorable circumstances for a professional competency development [16]. From a technology-enhanced learning perspective, understand the reasons of teachers using or not technology and what they should know in order to use it, requires further research [17, 18]. In this context, teachers requirement of more preparation is a relevant issue in Russia [19]. Moreover, what technologies do Russian teachers use related to learning activities in HPC is missing.

The "Inventory of Learning Activities with Technologies in the University" (IAATU) [20] is applied to assess what type of technology Russian university teachers are using to design learning activities and which is they level of self-confidence to use it. The problem of training specialists in the field of supercomputing has been widely discussed but, no from this perspective. This study is a contribution to new knowledge in the field of HTC, from the approach of teacher attitudes, specifically confidence, with the use of technology in the design of learning activities.

\section{The object of the study}

\subsection{Supercomputing in education}

The HPC concept circumscribes the computer server systems market, software, networking and services used to manage computationally intensive, data simulation and analytic problems [1]. The inclusion of parallel computing technologies in supercomputing education [3], specifically into the engineering curricula [1,5] is recommended. In fact, software is considered relevant into the HPC leadership [1], and the access to industry tasks, supercomputer technologies and systems [5].

Nevertheless, not all is about tools [3]. Indeed, skills demand a mixed understanding of a scientific discipline and computer 
technique [1]. Moreover, supercomputer centers require diverse educational activities [3], for example, complex scientific problems like methods of scientific inquiry [7], parallel programming technologies or architecture computer [3]. For this reason, a collaborative learning approach [7] could be useful to understand and explain the high complexity of computing systems [3] and to integrate HPC into the curricula.

\subsection{The use of technology in the design of learning activities}

Despite the recognition of HPC based simulation as belonged to the scientific inquiry and recommendations of integrating computational science methods in universities [1], it is difficult to add new content to the science and engineering curricula [1]. An option to solve this problem is the use of learning activities, which increase the motivation and the training results. Learning activities design is associated with the learning purpose, for example, test questions are used to evaluate knowledge and skills, test assignments for practical skills in parallel and distributed computing tasks, and demonstrations for teaching problemoriented specialists [5]. Furthermore, HPC and computational functional skills enrich through the use of technology in the learning process. For example, the use of technology let students experience by themselves the challenge of "writing meaningful simulations" without any access to HPC devices [21]. This learning activity through technology let them to understand HPC simulations that can be replicated on a big scale. This example illustrates how the use of technology in the design of learning activities can promote supercomputer technologies throughout the curriculum [5].

Instead of focusing in "what should we teach" or "what should be included in the new curricula" [5], the purpose of this research is related to explore how teachers are using technology and what kind of technology they are using to design learning activities.

\subsection{High Performance Computing competence: teacher attitudes}

Teachers are one of the target groups of supercomputing education infrastructure [5] in fact, due to they are often busy [5] their effort in teaching HPC is very valuable [21]. Knowledge and skills in parallelism concepts [3] are critical but, from the social psychology theory approach, also attitude. Attitude to technology influence its use [22]. Teachers' own technology practices and the type of technology activities they assign to students, let understand the development of teaching HPC from the teachers' perspective. A previous knowledge about teacher self-confidence in the technology used for learning activities design can be relevant to address an education program related to HPC [5]. Even more useful, if these teachers are going to train potential qualified candidates to HPC positions like"university graduates in mathematics, engineering, or physical sciences" [1].

Through IAATU, this study explores the use of learning activities with technologies and self-confidence by teachers at Russia universities.

\section{Methods}

\subsection{Population}

In the original study, 103 answers were collected from the online survey, since February to April, 2016. 52.4\% females and, $47.6 \%$ males. $43.7 \%$, in the age group of $31-40,17.5$ under 31 and $9.7 \%$ over $61.44 .7 \%$ of the teachers from Russia Universities. Re-test $(\mathrm{n}=48)$ was realized at Samara National Research University. 47,9\% women and 52,1\% men. In relation to age $16,7 \%$ between 20 and 30 years old, 27,1\% (31-40), 27,1\% (41-50), 12,5\% (51-60) and 16,7\% (61-70).

\subsection{Instrument}

In order to explore to what extent university professors are using technology as a pedagogical support resource, IAATU was used [20]. The adapted Russian version of IAATU [28], with 38 items distributed among 1 to 5 on a double Likert-type scale, collect demographic information such as: gender, age, university, field of knowledge and professional category. One scale refers to use frecuency asking "to what extent do you perform the activities described in the item?" while the other refers to the degree to which the teacher feels confident using the technology with the question "If you perform them, to what extent do you feel comfortable?" Two open questions in relation to technology not included and the use of technology at the University, are contemplated.

\subsection{Analysis}

Descriptive statistical methods were employed to analyze the level of the participants in self-confidence and in the use of technology. IBM SPSS Statistics and univariate were used to describe the characteristics and activities learning technologies frequency of the participants. In addition to pretest the Russian target language version of IAATU, re-test with target language subjects was conducted [23]. Temporal stability of the responses were analyzed on the same group of respondents with an interval of one month by means of a method based on the use of IAATU [24]. Moreover, the correlation coefficient between the two intervals of IAATU were examined [25], through Pearson Correlation Coefficient. Likewise, considering coefficient alpha and retest as index of reliability, were calculated [25]. The estimated internal consistency of each scale in the retest is provided in order to increase confidence in measure [26]. A Spearman's correlation was run to assess the relationship between technology use in learning activities and self-confidence on that technology, of a small sample of 48 teachers aged 31-50 years old at Samara National Research University. 
In order to analyze the content of open questions a frequency criterion was adopted. That is, higher was the number of the repetition of the same or similar terms in the answers, higher was the importance of such words. In this case, the words of the answers were also to be evaluated as word-concepts to count in order to establish which specific problems of access to technology are present among the teachers of Russian Universities. For example we got a word-concept as <lack of software> from analyzing and summing up an answer like: "I can not use technology in class, because there is no software to be used for economic tasks. Or at least I do not know them."

\section{Results and Discussion}

Scales of level of use (Cronbach's $\alpha=.91)$ and self-confidence $(\alpha=.93)$. Results re-test in relation to use $(\alpha=.93)$ and selfconfidence $(\alpha=.94)$ were reported with a value above Cronbach's $\alpha=.95$ scales. It showed very good reliability and internal consistency, which meets the criteria of reliability [27]. As previously reported, association between the use of learning activity and self-confidence in the Russian adaptation of IAATU were established [28].

The test-retest reliability coefficient of use scale (Figure 1) showed that there was a moderate positive correlation, which means there is a tendency for high use variable $(n=103)$ scores of the original test go with high use $(n=48)$ variable scores of retest (and vice versa), $r=.56, p=\leq .001$, with a $R^{2}=.323$. In the confident scale (Figure 2 ), there was a moderate positive correlation, which means there is a tendency for high self-efficacy variable in the original test $(\mathrm{n}=103)$ scores go with high selfefficacy variable scores in the re-test $(\mathrm{n}=48)$, and vice versa, $\mathrm{r}=.56, \mathrm{p}=<.001$, with a $\mathrm{R} 2=.322$.

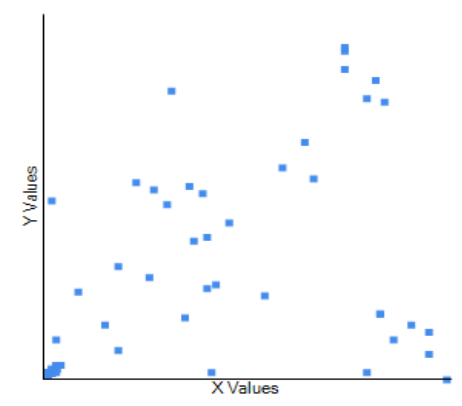

Fig.1. Pearson correlation use.

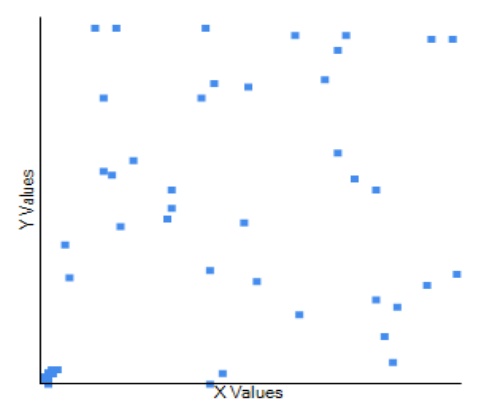

Fig.2. Pearson correlation self-confidence.

In relation to the re-test analysis, the average use and confidence score for each item were calculated (Table 1). Three groups of learning activities are identified in relation to the mean: low level (mean 1-2.5), medium (2.5- 3.5) and high (3.5-5). The average confidence is higher than the use. According to the same statistic (Table 2), up to 8 items have a high average use and confidence score (3.5-5). According with previous research, this results suggest that teachers' technology previous practice and confidence could determine their use of technology in their teaching [29].

Table 1. Results of the Spearman Rho correlation coefficient by items.

\begin{tabular}{|c|c|c|c|c|c|c|c|c|c|}
\hline & Item 1 & Item 2 & Item 3 & Item 4 & Item 5 & Item 6 & Item 7 & Item 8 & Item 9 \\
\hline Coefficient &, 521 & ,699 &, 287 & ,483 & ,698 & ,625 &, 720 &, 541 &, 845 \\
\hline \multirow[t]{2}{*}{ Sig. (bil) } & ,000 & ,000 & ,066 & ,001 & ,000 & ,000 & ,000 & ,002 & ,000 \\
\hline & Item 10 & Item 11 & Item 12 & Item 13 & Item 14 & Item 15 & Item 16 & Item 17 & Item 18 \\
\hline Coefficient & ,675 &, 822 & ,766 & ,731 & ,719 & ,929 & ,667 &, 890 & ,791 \\
\hline \multirow[t]{2}{*}{ Sig. (bil) } &, 000 &, 000 & ,000 &, 000 &, 000 &, 000 &, 000 & ,000 & 0 \\
\hline & Item 19 & Item 20 & Item 21 & Item 22 & Item 23 & Item 24 & Item 25 & Item 26 & Item 27 \\
\hline Coefficient & ,636 &, 853 & ,908 & ,839 & ,603 & ,752 &, 723 & ,925 & ,913 \\
\hline \multirow[t]{2}{*}{ Sig. (bil) } &, 000 &, 000 &, 000 &, 000 &, 000 &, 000 &, 000 &, 000 &, 000 \\
\hline & Item 28 & Item 29 & Item 30 & Item 31 & Item 32 & Item 33 & Item 34 & Item 35 & Item 36 \\
\hline Coefficient & ,947 & ,942 &, 812 &, 803 & ,919 & ,949 & ,910 & ,664 & ,971 \\
\hline \multirow[t]{2}{*}{ Sig. (bil) } &, 000 &, 000 &, 000 &, 000 &, 000 &, 000 &, 000 &, 000 &, 000 \\
\hline & Item 37 & Item 38 & & & & & & & \\
\hline Coefficient & ,644 & ,935 & & & & & & & \\
\hline Sig. (bil) & ,000 & ,000 & & & & & & & \\
\hline
\end{tabular}

In addition for five items, trust is high (3.5-5) and the use is medium (2.5-3.5): Item 4 "During my presentations and to facilitate my students' understanding of given concepts and ideas, I use video segments found on Internet" $(M=3.11 S D=1.18$, $M=4 S D=1.04$ ), Item 6 "Using the virtual platform, I provide my students with videos, demonstrations, simulations, experiences and/or cases to expand the information they received" $(M=2.52 S D=1.41, M=3.56 S D=1.48)$, Item 9 "I select text documents and I make them available to my students on the virtual platform in an effort to improve the reading understanding of my subject 
content" $(M=3 S D=1.53, M=3.78 S D=1.45)$, Item 13 "I design practical cases, using digital resources (videos, presentations, specific software, etc.), so that students can apply the theory learned to practical cases" $(M=3.25 S D=1.37, M=3.95 S D=1.18)$, Item 22 "I design problems in which students have to solve complex problems, using digital resources, similar to those a professional would use" $(M=3.38 S D=1.56, M=3.95 S D=1.37)$. Further research would be necessary in order to explore the reasons of this dissonance.

Spearman correlation (Table 1) was calculated. There was a strong positive correlation between use of technology and selfconfidence, which was statistically significant, $r_{S}=.7217, p=.0$ in all cases, except for item $3(M=3.65 S D=1.15, M=4.38$ $S D=0.85$ ), "During my presentations, I show students some type of simulations, demonstrations or examples based on digital resources, either my own, or available on the web, to clarify concepts and ideas". Unlike the initial results, the strength of the association of the items is not coincident in most cases. It would be necessary further research in order to determine the reasons.

According to the Mann-Whitney U tests only the level of use of item 18 "I design activities in which students must provide comments or given their point of view by means of personal or group blogs" differs according to sex (sig. 0.32). The confidence level of items 17 "I facilitate interaction with students outside the classroom by means of cellphone applications such as WhatsApp, Line, Twitter, Facebook, etc. to motivate the exchange of information, the resolution of doubts..." (sig. 0.15), 18 "I design activities in which students must provide comments or given their point of view by means of personal or group blogs" (sig. 0.15), 29 "I use virtual platform tools so that students can turn in homework/papers for my subject" (sig. 0.40), 30 "When assessing students, I use electronic portfolios, created on the actual platform or with specific online tools, for continual assessment" (sig. 0.002) differ according to gender. According to Kruskal, the level of use of items 20 "I ask students to write reports, essays, articles, etc. using reference management tools such as Zotero, Refworks, Mendeley, Endnote..." (sig. 0.009) and 38 (sig. 0.039) differed according to age. Only the confidence of 38 "During my teaching activities, I attend the terms of use for the digital materials that have a Creative Commons license" (sig. 0.46) differed according to age.

Table 2. Average use and confidence score.

\begin{tabular}{ccccc}
\hline Item & \multicolumn{2}{c}{ Use } & \multicolumn{2}{c}{ Confidence } \\
\hline & $\mathbf{M}$ & SD & $\mathbf{M}$ & SD \\
Item 1 & 3.90 & 1.13 & 4.58 & .65 \\
Item 3 & 3.65 & 1.15 & 4.38 & .85 \\
Item 10 & 4.31 & 1.05 & 4.61 & .68 \\
\hline Item 16 & 4.17 & 1.05 & 4.48 & .94 \\
\hline Item 19 & 3.51 & 1.33 & 4.21 & 1.04 \\
\hline Item 23 & 3.70 & 1.35 & 4.29 & 1.01 \\
\hline Item 35 & 4.02 & 1.29 & 4.28 & 1.14 \\
\hline Item 37 & 4.18 & 1.05 & 4.27 & 1.04
\end{tabular}

In order to complete the study content analysis of open questions from the original study ( $\mathrm{n}=103$ ), (Table 3) and (Table 4), following frequency criteria was applied. The first open question (Table 3) was: "If your learning process involves technologies that are not listed in the questionnaire, please describe them". It is highlighted that 6 answers specifically mentioned the System Management Learning (LMS) Moodle, as a technology not mentioned in IAATU. Due to Moodle is the main LMS used in Russian universities [30], and it is recommended in the learning administrative process and the training [7], its mention is also reasonable because of the geographically distributed country of Russia. Further research using IAATU should include an item in reference to Moodle, in order to accomplish a better adaptation of the questionnaire in the Russian higher education context.

Table 3. Technologies not listed in IAATU.

\begin{tabular}{lc} 
Type of technology & Number of answers \\
\hline Courses & $11 / 55$ \\
\hline Software & $9 / 55$ \\
\hline Others & $9 / 55$ \\
\hline No answers & $26 / 55$
\end{tabular}

The second open question (Table 4) refers "If you want to leave a comment on the questionnaire with questions on the educational process with the use of technology at the University". 13 answers mentioned the University as responsible of the use of technology by teachers. 9 of them referenced the lack of access and availability of technology and 3, training needs.

$\begin{array}{lc}\text { Table 4. Problems to implement technology. } \\ \text { Type of answer } & 17^{[\mathrm{A}]]} / 47 \\ \text { Questionnaire } & 13 / 47 \\ \text { University } & 6 / 47 \\ \text { Self-confidence } & 16 / 47 \\ \text { No answers } & 16 \text { of answers }\end{array}$

[A1] count 2 comments of one person as 2

Analysis showed that the more frequent problems reported by teachers at Russian University are technology acknowledge This allowed us to understand that at the present day Russian Universities suffers of an insufficient usage of technological means and structures. Another problem connected to the access of technology could be explained also with the actual lack of software knowledge of the newest technology adapted to be used for specific task in the didactic by the Engineering and Economy Faculties. Related to this, it is recommended the application of collaborative pedagogical approaches after the implementation of IT solutions [7], and it can be done by the design of learning activities.

The analysis of the self-confidence answer category cluster related to the teacher behaviour in relation to the use of technology for learning activities. 5 answers are related to the use of technology in relation to self-confidence, for example: "If I 
do not use any technology, it is not always due to the fact that I don't feel comfortable with it I can not know it, or do not have access or do not have enough time to do it." or "I can not use ready-made test (...)" and 1 to familiarity with ICT. 3 answers were a mix between comments in reference to the questionnaire (2), for example: "Not all the tools described in the questionnaire are familiar but, answers are formulated on the basis of analog products with similar functionality in the educational process", "I do a lot of issues of teacher training and blended learning technology development of online courses so, I would be more interested in questions of technology implementation strategies (...)"; and the University (2), "I'm open and ready to cooperate with the organization in e-learning. They need to train teachers in online methodology", "Lectures, laboratory and practices can not be transferred into the virtual space. Moodle is not available for all students".

It is plausible that this research may have limitations that could have influenced the results obtained. First, the sample size of our analysis are not enough to make generalizations about the more frequent problems reported by teachers at Russian University. As such, the findings should be taken with caution. Second, the high value of no answers to the open questions can be interpreted as perceived ambiguities in the meaning due to the fact that back-translation was not applied. Although it is not considered mandatory [31], it provides an assertion that the instrument is the same in two languages [23]. Third, retest assessments could introduce bias, due to the risk that respondents desire to appear consistent [32]. Furthermore, due to the IAATU was translated into a new language, from Spanish to Russian, to avoid the assumption of hypotheses about the dimensionality of a given set of items, exploratory factor analysis (EFA) could be applied [33]. Finally, considering that the support and maintenance of supercomputer centers require specific technology in order to automatic decision making on emergency situations, monitoring, or high performance tasks for the infrastructure, and others [3], an adaptation of the items to this context could be required.

Despite of the limitations, the results of this study coincide with previous research $[34,20]$ level of use of learning activity in teachers depend on their technology self-efficacy [35]. Furthermore, IAATU could serve as a tool to identify teachers that already have the attitude to serve as a bridge between the specialized knowledge of scientists and practitioners on the one hand, and scholars [21]. Even more, further research could consider the identification of teacher profiles in relation to their level of use of ICT in the design of learning activities [20]. Concerning to the use of digital technology, recent empirical studies pointed that patterns of technology use emerge from the frequency of use and by the nature of the activity [36]. Similarly, IAATU could be applied to define what kind of learning activity teachers are using: lecturer's presentation, communication, information management, application, evaluative or productive [20]. Due to the recommendation of a collaborative learning approach in supercomputing teaching [7] further research is required in order to determine what kind of learning activities could promote it.

Moreover, evidence has showed how teacher confidence in a task can be regulated by self-efficacy [37]. However, as confidence does not necessarily specify what the certainty is about [37], further data collection is necessary in order to determine exactly how confidence affects the use of technology in the design of learning activities at Russian Universities context.

\section{Conclusion}

This study contributes to the understanding of technology use and confidence (self-efficacy) in the design of learning activities from the teacher perspective into the higher education system in Russia. Relationship between teachers' own technology practices and the type of technology activities they assign to students has been examined. From a competency-based approach that acquires more holistic structure [38], this study highlight the importance of attitude, specifically, self-confidence as complementary to skills and knowledge in HPC. Previous research pointed advanced training for university teachers in various applied areas where supercomputing systems can be used for problem solving [4]. This study suggests that supercomputing education could enrich from an approach that take into account personal beliefs and actions based on attitudes, for example, teachers' confidence in their technology use. The approach of this research is a first step to understand the development of teaching HPC from the teachers' perspective.

\section{Acknowledgements}

This work was supported by the Ministry of Education and Science of the Russian Federation and the 5-100 program. As part of first author's doctorate thesis, the main author desires to transmit thanks to Professor Elenev Valeriy Dmitrievich, Director of the Institute of Aviation Technology at Samara National Research University, for invaluable support of this study.

\section{References}

[1] IDC, High Performance Computing in the EU: Progress on the Implementation of the European HPC Strategy, 2015.

[2] Zvacek S, Restivo MT, Uhomoibhi J, Helfert M. Computer Supported Education: 7th International Conference, CSEDU 2015. Lisbon, Portugal, May 23-25, 2015. Commun. Comput. Inf. Sci. 2016; 583: 152-168.

[3] Voevodin V. Efficiency of Exascale Supercomputer Centers and Supercomputing Education. Commun. Comput. Inf. Sci. 2016 ; $14-23$.

[4] Voevodin V, Gergel V. Supercomputing education: the third pillar of HPC 2010; 11(4): 117-122.

[5] Voevodin V, Gergel V, Popova N. Challenges of a systematic approach to parallel computing and supercomputing education. European Conference on Parallel Processing, 2015; 90-101.

[6] Ministry of Education and Science of the Russian Federation. Supercomputing Education Project. Russian Presidential Commission on modernization and technological development of Russian economy.

[7] Alexandrov N. Education and training for exascale. J. Comput. Sci. 2016; 14: 69-73.

[8] Chantrapornchai C, Uthayopas P. A Road to Student Cluster Competition for Thailand. 13th International Joint Conference on Computer Science and Software Engineering (JCSSE) A, 2016.

[9] Joiner DA, Gray P, Murphy T, Peck C. Teaching parallel computing to science faculty. Proc. Elev. ACM SIGPLAN Symp. Princ. Pract. parallel Program, 2006; 239.

[10] Berzins M, Kirby R, Johnson C. Integrating teaching and research in HPC: experiences and opportunities. Comput. Sci. 2005; 36-43.

[11] Gergel V, Meyerov I, Sysoyev A. Unified Assessment of Skills in Parallel and Distributed Computing. Fac. Comput. Math. Cybern. 2007; 5-6. 
Data Science / R. Martinez-Lopez, C. Yot, M. Sacchini

[12] Yanuschik OV, Pakhomova EG, Batbold K. E-learning as a Way to Improve the Quality of Educational for International Students. Procedia - Soc. Behav. Sci. 2015; 215: 147-155.

[13] Wozney L, Venkatesh V, Abrami P. Implementing Computer Technologies: Teachers Perceptions and Practices. J. Technol. Teach. Educ. 2006; 14(1): 173-207.

[14] Çatma Z, Corlu MS. How special are teachers of specialized schools? Assessing self-confidence levels in the technology domain. Eurasia J. Math. Sci. Technol. Educ. 2016; 12(3): 583-592.

[15]Lemon N, Garvis S. Pre-service teacher self-efficacy in digital technology. Teach. Teach. 2016; 22 (3): $387-408$.

[16]Zagrebina EI, Sharafetdinova ZG, Lushchik IV, Konyushenko SM, Ermoshina NV, Kosyakova EY, Ashrafullina GS. The Electronic Learning System as a Means of Forming Professional Competencies among University Students. J. Sustain. Dev. 2015; 8(3): $178-184$.

[17] Ertmer PA, Ottenbreit-leftwich AT. Ertmer \& Ottenbreit-Leftwich teacher knowledge confidence and beliefs 2010; 42(3): 255-284.

[18] Schweighofer P, Grünwald S, Ebner M. Technology Enhanced Learning and the Digital Economy: Int. J. Innov. Digit. Econ. 2015; 6(1): 50-62.

[19] Grigorevna MN. Pedagogical Maintenance of Future Teachers. Practice-oriented Training. $2015 ; 8$.

[20] Marcelo C, Domínguez C, Mayor Ruiz C. University Teaching with Digital Technologies. Comun. Rev. científica Iberoam. Comun. y Educ. 2015; 45: $117-124$.

[21] Hilpert J, Berlich R, Lürßen P, Zwölfer A, Barwind J. Teaching Simulations and High Performance Computing at Secondary Schools in the German State of Baden-Württemberg. Parallel and Distributed Processing Symposium Workshop (IPDPSW), 2015; 731-738.

[22] Hogg MA, Vaughan GM. Essentials of Social Psychology 2010; 16(3).

[23] Maneesriwongul W, Dixon JK. Instrument translation process: A methods review. J. Adv. Nurs. 2004; $48(2)$ : $175-186$.

[24] Beaton DE, Bombardier C, Guillemin F, Ferraz MB. Guidelines for the process of cross-cultural adaptation of self-report measures. Spine (Phila. Pa. 1976) 2000; 25(24): 3186-3191.

[25] Noar SM. The Role of Structural Equation Modeling in Scale Development. Struct. Equ. Model. A Multidiscip. J. 2003 ; 10 (4): $622-647$.

[26]Lovelace M, Brickman P. Best practices for measuring students' attitudes toward learning science. CBE Life Sci. Educ. 2013; 12(4): 606-617.

[27] Gliem JA, Gliem RR. Calculating, interpreting, and reporting Cronbach's alpha reliability coefficient for Likert-type scales. Midwest Research to Practice Conference in Adult, Continuing, and Community Education 2003; 1992: 82-88.

[28] Martinez-Lopez R, Reznichenko M, Yot C, Marcelo C. Inventory of Activities of Learning Technologies at University: Cross-Cultural Adaptation in the National Context of Russia. Eng. Educ. 2016; 20: 57-63.

[29] Chuang HH, Weng CY, Huang FC. A structure equation model among factors of teachers' technology integration practice and their TPCK. Comput. Educ. 2015; 86: 182-191.

[30] Grigorievich D, Gennadievna N. Russian Universities : Towards Ambitious Goals 2016; 11(8): $2207-2222$.

[31] Epstein J, Santo RM, Guillemin F. A review of guidelines for cross-cultural adaptation of questionnaires could not bring out a consensus. J. Clin. Epidemiol. 2015; 68(4): 435-441.

[32] Polit DF. Assessing measurement in health: Beyond reliability and validity. Int. J. Nurs. Stud. 2015; 52(11): 1746-1753.

[33] Polit DF, Beck CT. The Content Validity Index: Are You Sure You Know What's Being Reported? Critique and Recommendations. Res. Nurs. Health 2006; 29: 489-497.

[34] Yot C, Marcelo C. De la tiza al teclado: Enseñar y aprender con tecnologías digitales, Grupo de i, 2016.

[35] Marcelo C, Yot C. Pedagogies of working with technology in Spain. Adv. Res. Teach. 2015; 22B: 331-357.

[36] Area-Moreira M, Hernández-Rivero V, Sosa-Alonso JJ. Models of educational integration of ICTs in the classroom. Comunicar 2016 ; $24(47)$ : 79-87.

[37] Bandura A. Self-efficacy: The Exercise of Control. Encycl. Hum. Behav. 1997; 4: 71-81.

[38] Erganova NE, Shutova TV. Cluster model of designing competencies of a future vocational school teacher. Middle - East J. Sci. Res. 2014; 19(1): 8993. 